\section{Manuscripts not suitable for general readership of the South African Medical Journal}

To the Editor: Our most recent submission to the $S A M J$ received the following email response:

'The editors advisory group has reviewed the submission of Manuscripts finalised for journal submission by the University of the Free State School of Medicine medical editor: Journal response types and times [italics added] and has concluded that it is not suitable for the general readership of the South African Medical Journal. In view of this we regret that we are unable to accept it for publication. You might also consider submitting this manuscript to another, more suitable journal.

Thank you again for considering the South African Medical Journal for your work.'

As we pointed out in the rejected manuscript, this is not an uncommon response to our submissions to the SAMJ. Our study dealt with all manuscripts finalised for journal submission by the medical editor in the School of Medicine, University of the Free State, from 2014 to 2017. Ninety-five manuscripts were included, which comprised a total of 163 submissions. Twelve manuscripts were submitted to the SAMJ (the third-highest number of submissions to one journal), covering a wide range of clinical fields. They were mainly full-length articles $(n=9)$ and from postgraduate $(n=5)$ or staff projects $(n=4)$. All were rejected, with 'not suitable for general readership' or 'out of scope of journal' being the main reasons $(n=9)$. No reason for the rejection was given for two manuscripts, and one manuscript had numerous methodological and presentation issues. The latter manuscript was subsequently revised and resubmitted, and accepted on the day it was resubmitted. The average time to first response from the journal regarding the rejections was 7 days (range 0 - 63 days).

What is particularly noteworthy is that SAMJ submissions made up $8.0 \%$ of all submissions included in our study, $14.6 \%$ of all rejected submissions, and $36.0 \%$ of all submissions rejected due to out of scope of journal/not suitable for general readership. The latter percentage seems to indicate that we really do not understand what sort of manuscript is actually of interest to the general readership of the SAMJ. We suspect that other authors may also benefit from some elucidation from the journal in this regard. It will also be of interest to know how the journal determines what is of interest to their general readership.

\section{Gina Joubert}

Head of Department/associate professor, Department of Biostatistics, Faculty of Health Sciences, University of the Free State, Bloemfontein, South Africa

gnbsgj@ufs.ac.za

\section{Theanette Mulder}

Medical editor/writer, School of Medicine, Faculty of Health Sciences, University of the Free State, Bloemfontein, South Africa

\section{Wilhelm Johannes Steinberg}

Associate professor/principal family practitioner, Department of Family Medicine, Faculty of Health Sciences, University of the Free State, Bloemfontein, South Africa

\section{Johan Botes}

Senior officer, Department of Family Medicine, Faculty of Health Sciences, University of the Free State, Bloemfontein, South Africa

The Editor replies: I thank the authors of this letter for raising their concerns in a courteous way and with supplementary data. Their concerns are noted.

I am not sure whether the authors are aware that the $S A M J$ has a pre-review committee of independent academics, covering a range of specialties, who see each article submitted weekly and decide whether or not to send it for further review. The wording of a generic rejection message is always going to be vague, as the reasons for rejection before review are just too diverse. A submission may be unsuitable simply because the research question or the study itself is poor, or it may not be suitable for a general medical journal but rather of interest only to specialists in a particular field, or it may be completely outside the scope of the journal altogether, such as social science studies that touch on medical topics. A common problem is studies that report on single-centre audits, with little or no generalisability. Submissions of this type are becoming increasingly frequent as universities require their registrars to provide published papers as part of a master's thesis.

The SAMJ has an acceptance rate of $\sim 20 \%$, and providing authors with detailed reasons for rejection in each instance becomes impractical, although I not infrequently do provide some input, particularly if the reason for rejection is queried.

As with any journal, it should be possible to determine what is or isn't an acceptable topic simply by reading a few issues of the journal to see what types of papers have made it through the initial editorial board and the peer review process. I hope that this clarifies some of the issues. Perhaps it is time to change the generic rejection message!

S Afr Med J 2019;109(2):65. DOI:10.7196/SAMJ.2019.v109i2.13772 